\title{
Primary Cutaneous Mucinous Carcinoma Presenting as an Unusually Large Lesion - A Rare Case Report
}

\author{
Jiby Soosen Ninan ${ }^{1}$, Ajithakumari K. ${ }^{2}$, Tony Mathew ${ }^{3}$ \\ ${ }^{1,2}$ Department of Pathology, Believer's Church Medical College, Pathanamthitta, Kerala, India. \\ ${ }^{3}$ Department of Surgery, Believer's Church Medical College, Pathanamthitta, Kerala, India.
}

\section{INTRODUCTION}

Primary cutaneous mucinous carcinoma (PCMC) also known as primary mucinous carcinoma of the skin (PMCS) or primary mucinous eccrine carcinoma (PMEC) is a rare malignant adnexal tumour of eccrine origin. Many visceral mucinous carcinomas especially of the breast and gastrointestinal tract can metastasize to the skin mimicking PCMC. Hence it is very important to rule out metastatic mucinous carcinomas before making a diagnosis of PCMC. Usually, PCMC presents as a slowgrowing tumour of considerably smaller size compared to our case. The large size and shorter duration are the key features of this case report.

Here we report an unusually large-sized rare malignant tumour of skin appendage. Our patient was a 54-year-old lady who presented with progressive swelling of one year duration in the right frontoparietal area. Ultrasonography showed an ill-defined lesion in the subcutaneous plane with multiple cystic spaces within it. No bone involvement was noted. The excised lesion measured 13 × 7 × 2 cms and was diagnosed as primary cutaneous mucinous carcinoma on histopathological examination. The possibility of cutaneous secondaries from elsewhere was ruled out by detailed clinical and radiological investigations. The case is reported considering the unusually bigger size and shorter duration of this rare entity.

\section{PRESENTATION OF CASE}

A 54-year-old lady presented with a complaint of progressive swelling for one year involving the right frontoparietal region of the scalp and adjacent forehead region. [Figure 1A] The swelling measured $15 \times 8 \mathrm{cms}$. A few small satellite lesions were present at the periphery of the main lesion. Superficial skin over the lesion was intact and appeared normal. There was no associated pain or bleeding manifestations. No lymph nodes were identified in the vicinity. Ultrasonography showed an ill-defined lesion in the subcutaneous plane with multiple cystic spaces within it. No bone involvement was seen. Considering the age of the patient and the location of the lesion a detailed clinical workup was done to look for a primary elsewhere. Routine blood and urine investigations were within normal limits. A mammogram study of both breasts appeared normal.

\author{
Corresponding Author: \\ Dr. Ajithakumari K., \\ Professor, \\ Department of Pathology, \\ Believer's Church Medical College, \\ Pathanamthitta, Kerala, India. \\ E-mail: ajithakdr@gmail.com
}

DOI: $10.14260 / j e m d s / 2021 / 599$

How to Cite This Article:

Ninan JS, Ajithakumari $K$, Mathew $T$. Primary cutaneous mucinous carcinoma presenting as an unusually large lesion - $a$ rare case report. J Evolution Med Dent Sci 2021;10(34):2939-2941, $10.14260 / \mathrm{jemds} / 2021 / 599$ DOI:

Submission 31-01-2021,

Peer Review 23-06-2021,

Acceptance 30-06-2021,

Published 23-08-2021.

Copyright (c) 2021 Jiby Soosen Ninan et al. This is an open access article distributed under Creative Commons Attribution License [Attribution 4.0 International (CC BY 4.0)] 
HRCT Thorax and CECT abdomen and pelvis did not reveal any abnormality. Gastrointestinal endoscopy also was within normal limits. With these findings, surgical excision of the lesion was done. The superficial skin over the main lesion was cut open, everted and the underlying tumour mass removed [figure 1B]. The specimen we received showed scalp skin tissue with a raised, grey-white, gelatinous, vaguely nodular lesion measuring $13 \times 7 \times 2 \mathrm{cms}$ [Figure 1C]. The under surface of the scalp skin was smooth. On cutting through the lesion showed a uniform gelatinous cut surface. Histology of the lesion showed a neoplasm with tumour cells floating in pools of mucin and forming lobules intervened by fibrous septa. The tumour cells were arranged as nests, cords and glandular formations. These cells were monomorphic cuboidal cells with dense hyperchromatic nuclei showing minimal atypia.[Figure 1D] On immunohistochemistry, the tumour cells were positive for CK7 [Figure 2A] and negative for CK20 [Figure 2B]. These cells were also positive for P63 [Figure 2C] and ER [Figure 2D]. CDX2, HER2 / neu, were all non-reactive while GATA 3 was immunoreactive. With the above findings, a diagnosis of primary mucinous cutaneous carcinoma was made.
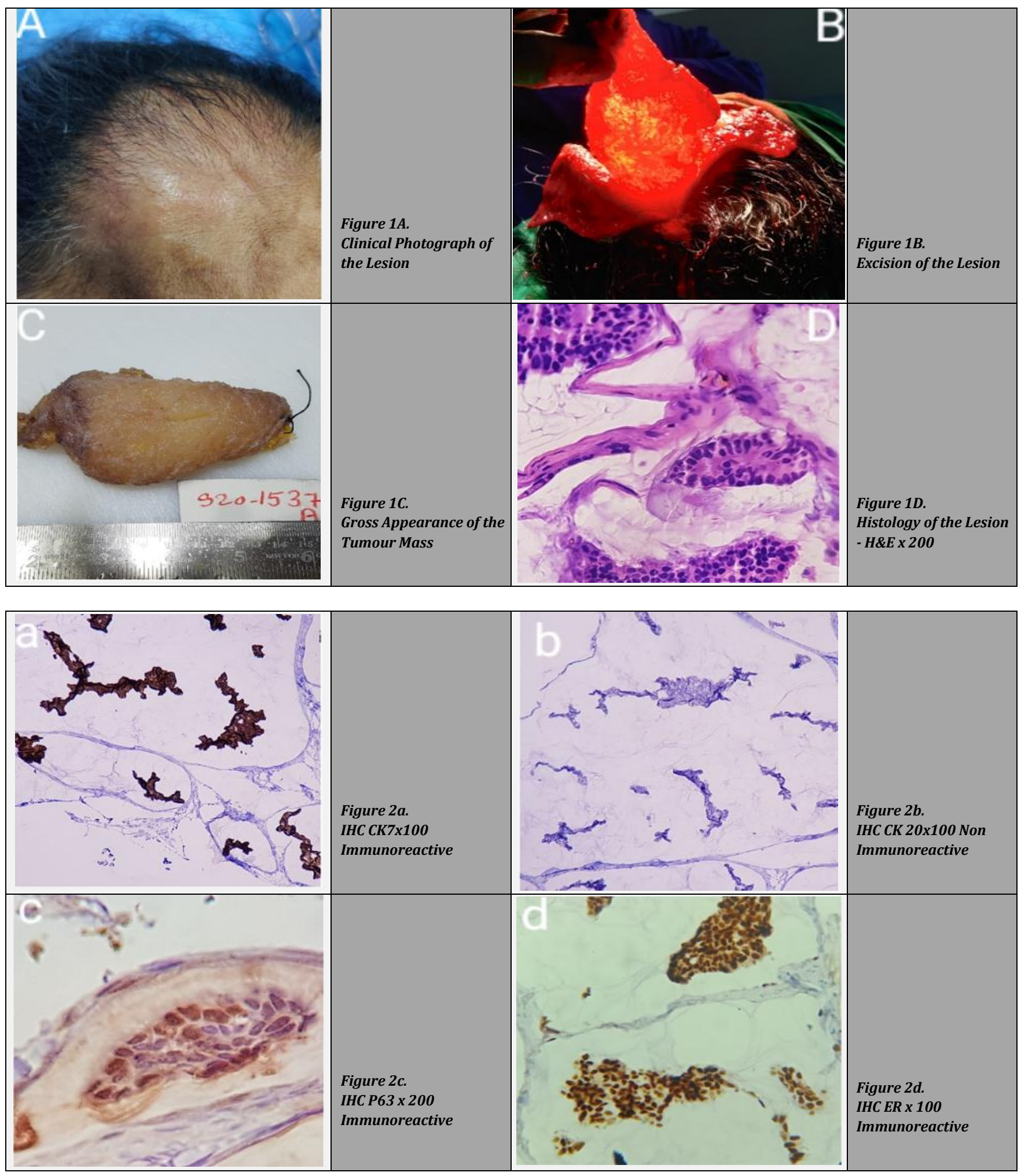


\section{DISCUSSION}

PCMC is a rare malignant neoplasm of eccrine glands. Initially described by Lennox et al. in 1952. The prevalence rate is unknown; however, Breiting et al. in a Danish population-based study reported an incidence rate of $<0.1$ per million people in 2007. ${ }^{1}$ This tumour is generally small, slowgrowing with frequent local recurrence but has the potential to metastasize. ${ }^{2}$ In our case though the lesion was large, the patient gave a history of only one-year duration. The most common age group of involvement is the fifth to the seventh decades with a male predilection. The most common site of involvement is on the head favouring scalp and face near eyelids. Rare sites include axilla, trunk, perianal area, vulva and lower extremities. Literature review has shown the lesion to range in size from $1 \mathrm{~cm}$ to $5 \mathrm{cms}^{3}$

In this case, the lesion measured $13 \mathrm{cms}$ across the greatest diameter. To the best of our knowledge, such a large PCMC has never been reported before. Differential diagnoses of PCMC are metastatic mucinous carcinomas [MMC] arising from the breast, gastrointestinal tract, salivary glands, lacrimal glands, nose, paranasal sinuses, bronchi, renal pelvis, and ovary. ${ }^{4}$ Morphologically metastatic carcinoma especially from the breast and colon very closely mimic primary eccrine mucinous carcinoma of the skin. ${ }^{3}$

Histologically it is almost impossible to differentiate these lesions. Immunohistochemically also shows a considerable overlap between MMC from breast and PCMC. However, this distinction becomes very important given the poor prognosis of MMC. In our case, the possibility of metastatic mucinous carcinoma was excluded by clinical, radiological, and endoscopic evaluation along with immunohistochemical studies. The presence of a myoepithelial component in PCMC as was seen in our case is considered as a morphologic parameter to distinguish it from MMC from either breast or sites elsewhere in the body. ${ }^{5}$ Few case reports have depicted these tumours to have focal neuroendocrine differentiation with positive chromogranin and synaptophysin immunohistochemistry. ${ }^{6}$

Local excision is the treatment. However, due to the high recurrence rate, adequate excision with generous margins of at least 1.5 to $2.5 \mathrm{cms}$ is recommended. Bad prognostic features associated with recurrence and metastasis include younger age of presentation, Asian background, tumour on the trunk, and a swelling size of more than $1.5 \mathrm{cms}^{7}$

\section{CONCLUSIONS}

PCMC is considered a rare skin adnexal neoplasm with indolent behaviour. But in our case, the patient presented with a considerably large sized lesion with satellite nodules with a history of one-year duration only. Hence this case becomes unique compared to other PCMCs reported in the literature.

Financial or other competing interests: None.

Disclosure forms provided by the authors are available with the full text of this article at jemds.com.

\section{REFERENCES}

[1] Breiting L, Christensen L, Dahlstrøm K, et al. Primary mucinous carcinoma of the skin: a population-based study. Int J Dermatol 2008;47(3):242-5.

[2] Kazakov DV, Argenyi ZB, Brenn T, et al. Mucinous Carcinoma. In: WHO Classification of Skin Tumors. $4^{\text {th }}$ edn. Lyon: IARC Press 2017: p. 166.

[3] Goyal R, Tanveer N, Singh UR. Primary mucinous eccrine adenocarcinoma: a rare skin adnexal tumor at an unusual site. J Cytol 2019;36(1):71-2.

[4] Mardi K, Diwana VK. Primary cutaneous mucinous carcinoma: a rare entity. Indian Dermatol Online J 2011;2(2):82-4.

[5] Qureshi JS, Salama ME, Chitale D, et al. Primary cutaneous mucinous carcinoma: presence of myoepithelial cells as a clue to the cutaneous origin. Am J Dermatopathol 2004;26(5):353-8.

[6] Kim JB, Choi JH, Kim JH, et al. A case of primary cutaneous mucinous carcinoma with neuroendocrine differentiation. Ann Dermatol 2010;22(4):472-7.

[7] Sistla R, Afroz T, Narayanswamy J. Primary mucinous adenocarcinoma of skin: myoepithelial cells are a clue to its diagnosis. Indian J Dermatol 2018;63(2):165-7. 